\title{
Geologia
}

\section{Gruta do Salitre (MG 361): geoespeleologia e espeleotemas}

\author{
Cláudio Maurício Teixeira da Silva \\ M.Sc., Professor de Espeleologia do DEDEO/UFOP \\ E-mail: claudiom@degeo.ufop.br \\ Paulo Rodrigo Simões \\ Aluno da graduação da UFOP e membro da SEE \\ E-mail:prsimoes@yahoo.com
}

\section{Resumo}

Esse artigo sintetiza os estudos realizados na Gruta do Salitre, situada a $5 \mathrm{~km}$ de Cordisburgo, MG, e que está cadastrada sob o número MG 361 junto ao Cadastro Nacional de Cavidades da Sociedade Brasileira de Espeleologia (SBE, 1991). As atividades constaram do mapeamento topográfico parcial da caverna, descrições dos espeleotemas e da rocha hospedeira e interpretação da gênese da cavidade. Observações e tomadas de fotografias foram feitas nos locais de maior interesse.

A gruta desenvolveu-se em rochas carbonáticas, estratificadas, dobradas e fraturadas da Formação Lagoa do Jacaré. A cavidade tem a forma, em planta, linear meandrante, com perfil predominantemente horizontal e secundariamente inclinado. $\mathrm{O}$ desenvolvimento da caverna envolve pelo menos quatro fases de evolução, desde o processo freático ao vadoso, com desenvolvimento dos salões por incasão. Os salões finais da caverna são os mais ornamentados (fase vadosa) com ocorrência de vários espeleotemas, entre os quais se destacam, por sua beleza, os excêntricos (helictites), por sua raridade, os blisters ou esferas de calcita e, por sua gênese, os cristais de calcita "dente-de-cão".

Palavras-chave: Geoespeleologia, Espeleotemas, Gruta Salitre.

\begin{abstract}
This paper reports the activities developed by SEE's members and students of the speleology course realized by DEGEO/EM/UFOP during the last two years at Gruta do Salitre (MG 361, SBE 1991), Cordisburgo/MG. The activities included a partial mapping of the cave, observation of speleothems and inferences on the cave genesis. The methodology used was that described by Cavalcanti (1996) in which a topographical survey is made by using a magnetic needle fixed by a tripod. Tape measurements, drawing boards, candles, gradation rulers and machine pencils were also used. At most interesting places, observations and photographs were taken.
\end{abstract}

A partial topographic map of the cave was produced. The cave developed in a stratified, folded and fractured carbonatic rock from Lagoa do Jacaré Formation. The cave shape is typically linear meanderly with a profile predominantly horizontal and secondarily inclined. The cave evolved through four phases from phreatic to vadose processes, with chamber development by breakdown. The last chambers are the most ornamented ones (vadose phase) and show many speleothems which highlight the eccentrics (helictites) because of its beauty, the blisters because of its rare occurrence and the dogtooth calcite spar by its genesis.

Keywords: Spaeleology, Speleothems, Salitre Cave.

Artigo recebido em 19/03/2002 e aprovado em 18/10/2002 


\section{Introdução}

O presente artigo refere-se aos resultados auferidos durante os estudos e trabalhos executados na Gruta do Salitre (MG 361), pelos membros da Sociedade Excursionista Espeleológica (SEE), pelos alunos da disciplina Espeleologia do Departamento de Geologia da Universidade Federal de Ouro Preto (UFOP). Os estudos foram autorizados pelo Ibama/ Cecav/MG.

Durante o levantamento topográfico, foram utilizados os equipamentos e a metodologia de levantamentos espeleométricos descritos por Cavalcanti (1996).

\section{Localização e acesso}

A Gruta do Salitre localiza-se no município de Cordisburgo/MG, cerca de $5 \mathrm{~km}$, a leste, da sede desse município (Figura 1).

O acesso é feito pela BR 040, a partir do anel rodoviário de Belo Horizonte, onde se percorre $78 \mathrm{~km}$, nessa rodovia, até o trevo de acesso à cidade de Cordisburgo. Desse trevo até o centro da cidade são percorridos mais $23 \mathrm{~km}$, em estrada asfaltada.

A gruta foi cadastrada, junto à SBE, sob o número 361, pelo NAE (Núcleo de Atividades Espeleológicas) de Belo Horizonte. Localiza-se nas coordenadas 1907'17'de latitude S e 44²8'24' de longitude $\mathrm{W}$, com altitude de $730 \mathrm{~m}$, projeção horizontal de $1.098 \mathrm{~m}$ e desnível de 43m (SBE 1991).

\section{Geologia regional}

A área insere-se na Unidade Geomorfológica conhecida como Depressão Sanfranciscana, segundo Boaventura et al. (1977). As formas de relevo constituem-se de formas de aplainamento e formas cársticas.

Segundo Magalhães (1988), a região da área analisada é composta por unidades do Supergrupo São Francisco, mais especificamente do Grupo Bambuí. As unidades são limitadas, a leste, pelas frentes de empurrões presentes na Cor- dilheira do Espinhaço e, ao sul, o limite faz-se com os gnaisses e migmatitos do embasamento cristalino.

O Grupo Bambuí pode ser dividido em três unidades principais: uma basal, predominantemente carbonática; uma intermediária, composta por clásticos finos e uma terceira, que se constitui em um segundo nível de carbonatos escuros intercalados com clásticos finos (Magalhães, 1988). Essas unidades correspondem, da base para o topo, às formações Sete Lagoas, Serra de Santa Helena, Lagoa do Jacaré, Serra da Saudade e Três Marias.

A gruta está inserida no domínio dos litotipos do Grupo Bambuí (Figura 2), mais especificamente da Formação Lagoa do Jacaré.

\section{Geologia da gruta}

A rocha calcária, hospedeira da Gruta Salitre, compõe-se de um calcário estratificado, com intercalações centimétricas e decimétricas de calcarenito cris- talino, cinza médio a escuro, e siltitos e argilitos centimétricos. Alguns desses níveis de siltitos apresentam ripple marks assimétricas, com cerca de $2 \mathrm{~cm}$ de altura de onda. Essas ondulações, associadas às litologias, evidenciam um ambiente marinho raso sob influência de ondas. Esse calcário estratificado apresenta-se dobrado. Ocorrem pequenas dobras (até 0,5m de amplitude) intra-estratais e grandes dobras (5 a 10m de amplitude), assimétricas e vergentes para oeste. As grandes dobras controlam partes dos condutos da caverna. A rocha hospedeira apresenta, também, fraturas diversas, como juntas verticais, espaçadas, com direções NW-SE e NE-SW. Algumas das fraturas parecem indicar deslocamentos das camadas adjacentes, nesses planos, caracterizando falhamentos com deslocamentos inversos.

Como depósitos sedimentares alóctones, é comum se observar a presença de cascalheiras recentes e pretéritas na gruta. No salão da entrada, próximo à boca, observa-se um nível de conglome-

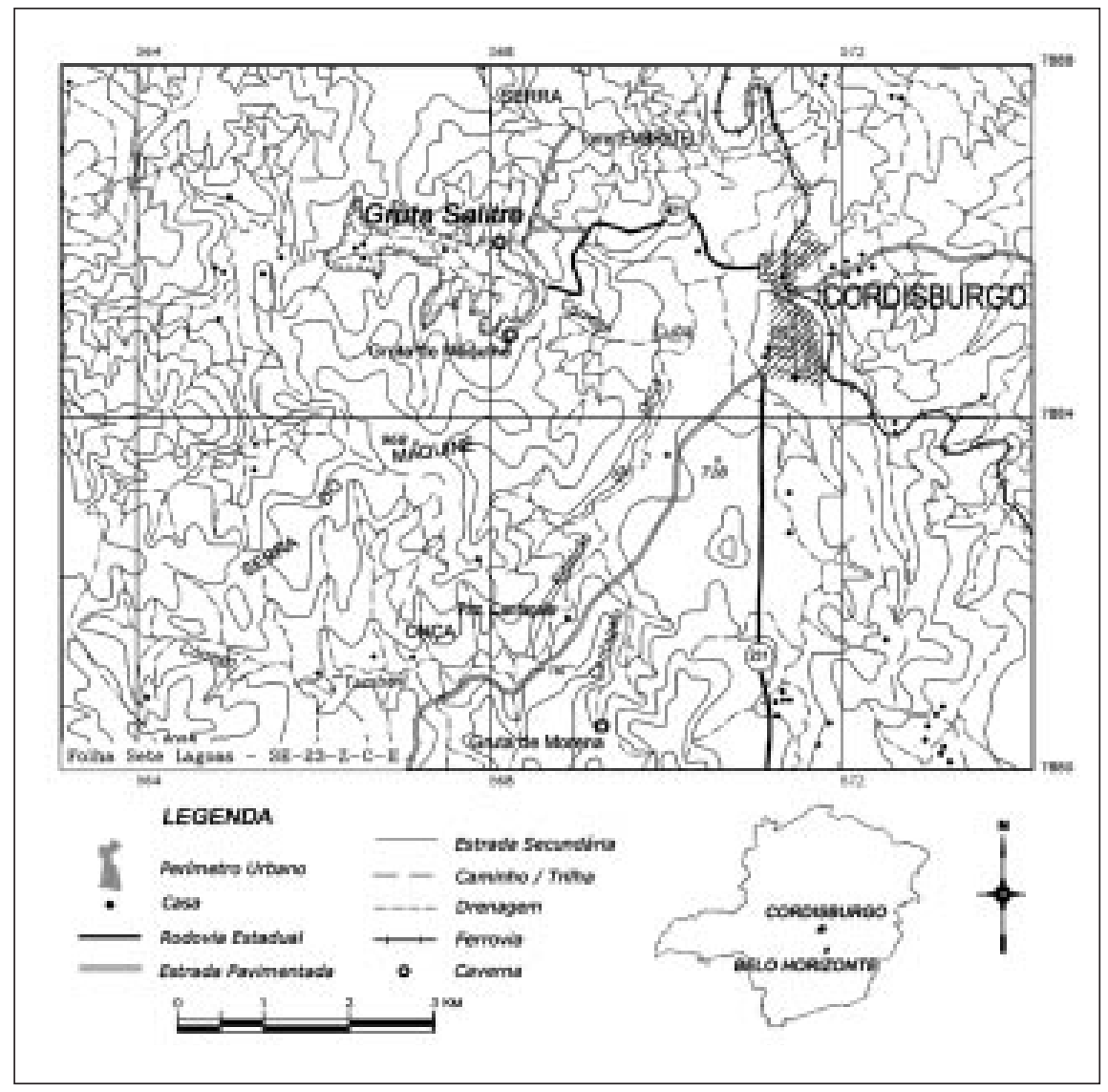

Figura 1 - Mapa de localização e acesso da Gruta do Salitre. 
rado cimentado por óxidos de ferro, no topo da galeria, próximo ao teto do salão. Os depósitos recentes de cascalhos, areias e lama (argila mais silte) são comuns, devido à presença de fluxo aquoso, sazonal, na maioria das galerias (Figura 3). Encontram-se restos de ossos, com até $30 \mathrm{~cm}$ de comprimento, limonitizados, nesses sedimentos.

Os depósitos autóctones principais são os blocos abatidos, pelo processo de incasão, e os espeleotemas. Os espeleotemas são mais comuns nos salões finais da caverna. Entre esses encontramse, em ordem decrescente de freqüência, os seguintes: estalactites, estalagmites (Foto 1), cortinas (Foto 2), colunas, escorrimentos em forma de cascatas e "lustres" (Foto 2) travertinos, principalmente minitravertinos, com ou sem "calcita cintilante", helictites (Foto 3), calcitas "dentes-de-cão" (Foto 4) e bolhas (blisters) (Fotos 5 e 6 ). A respeito da ocorrência desses últimos tipos, algumas considerações serão feitas no item 6 , a seguir.

A boca de entrada da Gruta do Salitre fica em um paredão abrupto, cerca de meia altura do paredão do dolinamento. Abaixo da boca existe um sumidouro, por onde o ribeirão da dolina desaparece.

Internamente a cavidade é percorrida por um fluxo d'água, de pequena vazão (não medida), sazonal, que depende do volume de precipitação pluviométrica externa. Esse fluxo tem sua exsurgência, aparecimento interno, na base do salão das calcitas "dentes-de-cão" e percorre a gruta até próximo da sua entrada, quando desaparece sob blocos abatidos.

Em suma, a cavidade tem seu maior desenvolvimento no nível epifreático, com suas extremidades em níveis mais superiores, vadosos.

A cavidade tem partes dos condutos em teto baixo, com piso sobre depósitos aluvionares recentes, que, durante as épocas das chuvas, podem se inundar completamente, trazendo riscos de vida para os exploradores mais desavisados.

\section{Espeleogênese}

A Gruta do Salitre é, principalmente, uma cavidade de origem freática que evoluiu até a fase vadosa. Indícios de condutos de pressão hidrostática podem ser observados no salão de entrada da caverna. $\mathrm{O}$ fluxo aquoso percorre o acamamento inclinado da rocha hospedeira e vai dissolvendo essa rocha. Quando a dissolução atinge o limite de estabilidade do maciço, ocorrem os desabamentos gravitacionais, da porção superior do pacote rochoso, originando os salões de abatimento, cujo processo é conhecido como incasão (Lino, 1989). Grandes abatimentos de rochas podem ser observados no interior da cavidade.

A possível origem dessa caverna está ligada a fases de desenvolvimento, que podem ser resumidas da seguinte maneira:

1. Dissolução de interseções de juntas e de interseções de juntas com o acamamento da rocha, sob pressão hidrostática, no nível freático (Primeira Fase).

2. Abaixamento do nível freático e desenvolvimento dos condutos por circulação de fluxo aquoso livre, em zona anfíbia, contato água-ar, e deposição de depósitos de cascalhos, areias e lama (Segunda Fase).

3. Processo de confinamento da gruta, com inundação do salão, onde ocorrem as calcitas "dentes-de-cão". Esse salão permaneceu inundado com a conseqüente deposição desses cristais de calcita no teto do salão. No salão seguinte, a jusante, espessos depósitos argilosos atestam a veracidade desse inundamento (Terceira Fase).

4. Abatimento de partes do teto por incasão e contínuo abaixamento do nível freático com desenvolvimento parcial por fluxo vadoso, acima do nível epifreático, com abandono de salões e galerias superiores, que se tornam, cada vez mais, ornamentadas por espeleotemas (início e parte final da gruta) (Quarta Fase e Fase Atual).

\section{Espeleotemas}

Entre os espeleotemas da Gruta do Salitre, destacam-se as esferas de calcita (blisters), os helictites e a calcita "dente-de-cão".

Os blisters e os helictites são depósitos de águas de exsudação (Lino, 1989, Hill \& Forti, 1997, Teixeira da Silva, 1997), enquanto a calcita "dente-de-cão" é um depósito de água estagnada (idem). "Blisters" ou esferas (Lino, 1989) são pequenas protuberâncias esféricas, ocas, que ocorrem nas paredes inclinadas das cavernas. Segundo esse autor, o espeleotema é de origem desconhecida e, ainda, não mereceu nenhum estudo entre espeleólogos brasileiros.

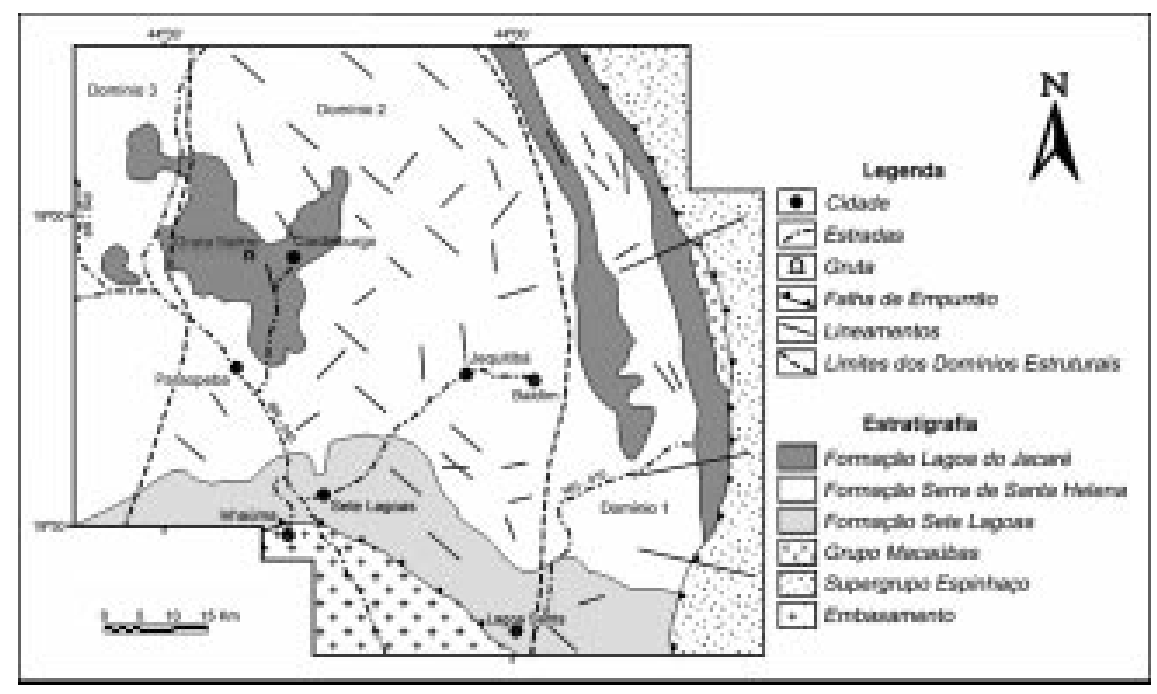

Figura 2 - Mapa geológico simplificado e domínios estruturais da região de Cordisburgo, MG. (Modificado de Magalhães, 1988.) 
Hill e Forti (1997) caracterizam três tipos de espeleotemas esféricos e ocos: balões (balloons), esferas (blisters) e bolhas (bubbles). As esferas são depósitos protuberantes, semi-esféricos, formados por argila, areia ou por uma variedade de diversas substâncias minerais como a opala e a gipsita. Aparentemente são semelhantes aos balões e bolhas, mas, por inúmeras razões, acredita-se ser um outro tipo de espeleotema. As esferas não são flutuações livres como as bolhas, ao contrário, elas são normalmente encontradas anexadas às paredes, às coberturas e crostas, aos coralóides, aos escorrimentos ou às cascatas. Ainda, segundo esses autores, algumas vezes os "blisters" estão associados e provavelmente são uma gradação das crostas com protuberâncias.
As esferas não são, também, balões, ainda que suas gêneses sejam similares. Os balões são espeleotemas do tipo sacos e são pendentes e associados com um substrato de leite-de-lua (moonmilk) e usualmente são compostos de hidromagnesita pura. As esferas são espeleotemas semi-esféricos semelhantes a protuberâncias e estão associadas com um substrato cristalino e são compostas por uma variedade de minerais. A origem das esferas comporta duas explicações (Hill \& Forti, 1997). Umas delas diz que a decomposição de matéria orgânica, no sedimento argiloso da caverna, produz bolhas de gás causando uma superfície que se torna coberta por uma protuberância de calcita. A outra está relacionada com a circulação de água por capilaridade num mecanismo que concorda com o experimento de Pobéguin (1957), que obteve objetos semelhantes a esferas no topo de vidro capilar. No caso das esferas, parece que um pequeno botão forma-se sobre um orifício da parede através do qual a água é continuamente alimentada por pressão. Forças de cristalização subseqüentes empurram a incrustação inicial para fora da parede, criando, assim, uma cavidade sobre o orifício, formando uma esfera que cresce, continuamente, em diâmetro. Desde então toda a solução emitida evapora-se e minerais, como a gipsita e a opala, depositam-se com a calcita. A heterogeneidade do material pode ser parcialmente responsável pelas aberturas rachadas das esferas.

As esferas de calcita da Gruta do Salitre (Fotos 05 e 06) ocorrem no fim do conduto do rastejamento, na entrada do salão, na parede esquerda da drenagem (Figura 03). Essas esferas têm até $2,5 \mathrm{~cm}$

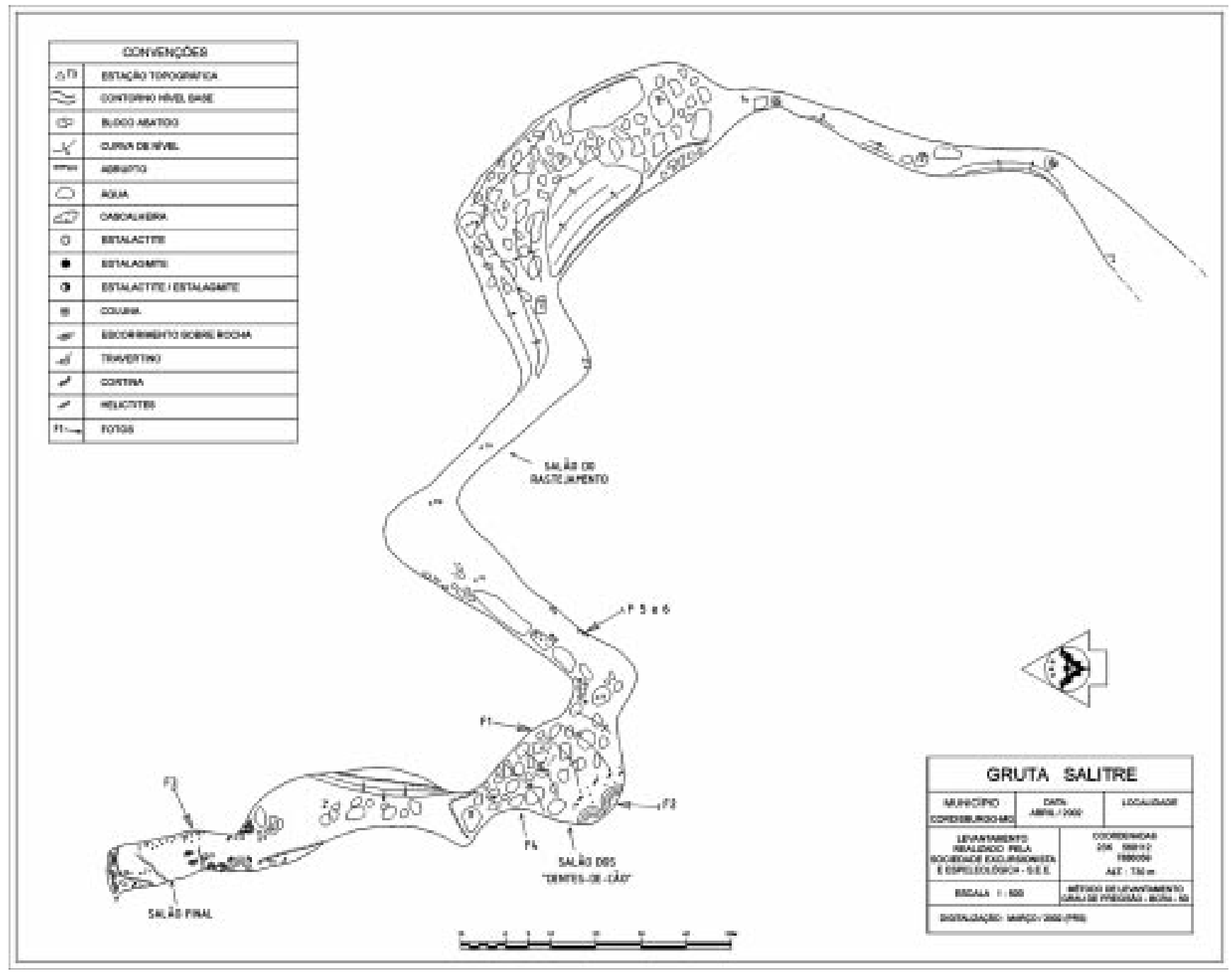

Figura 3 - Planta baixa parcial da Gruta do Salitre, executada pela equipe da S.E.E. (Sociedade Excursionista e Espeleológica). 


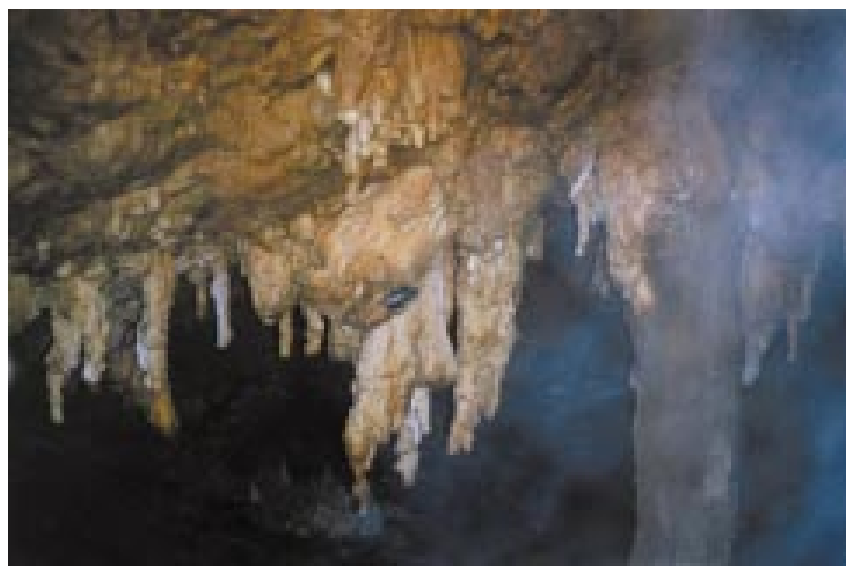

Foto 1 - Estalagmites no salão da calcita "dente-de-cão".

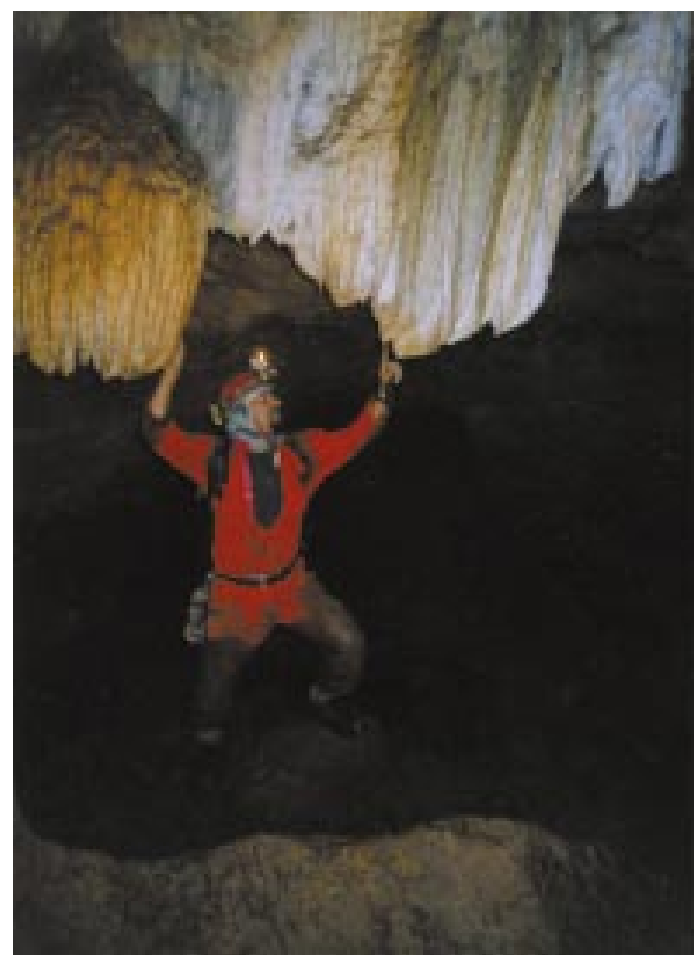

Foto 2 - Cortinas e escorrimentos em forma de "lustres" no salão da calcita "dente-de-cão".

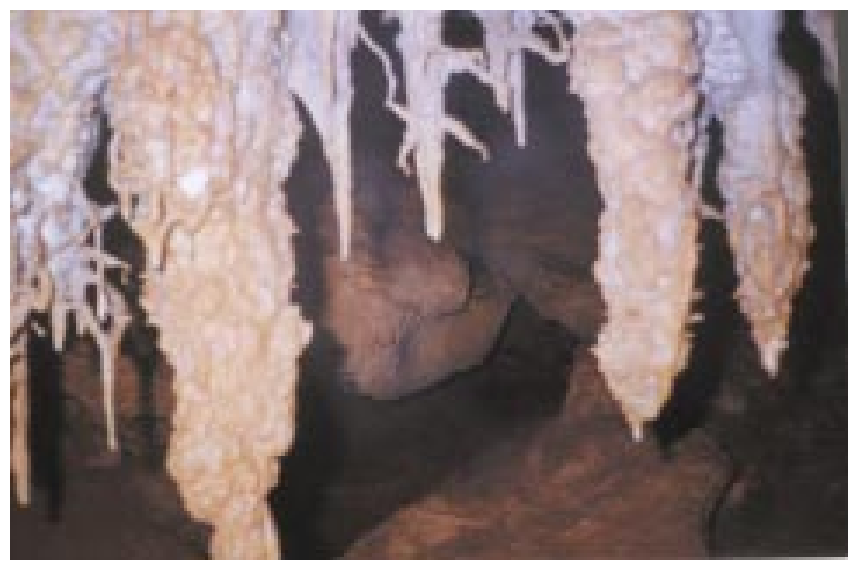

Foto 3 - Helictites centimétricos sobre estalactites decimétricas, salão final da gruta.

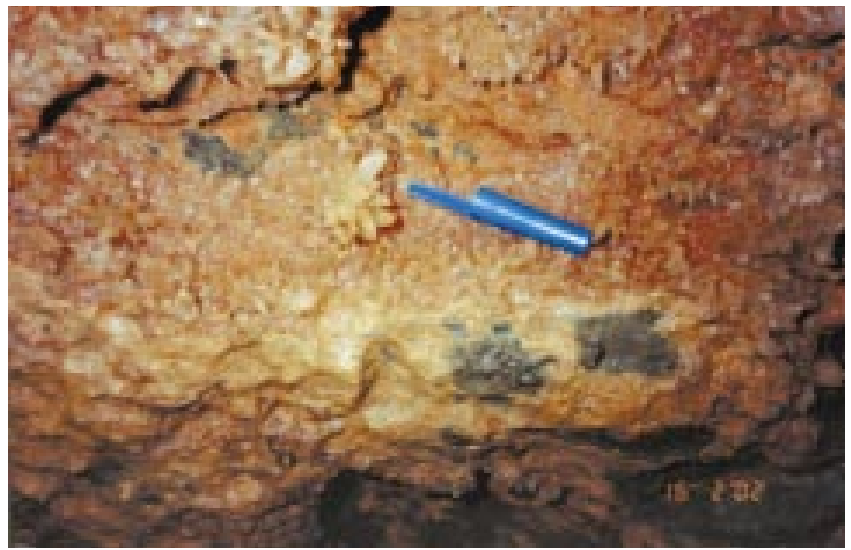

Foto 4 - Calcitas "dentes-de-cão", centimétricas a milimétricas, no teto do salão de mesmo nome.

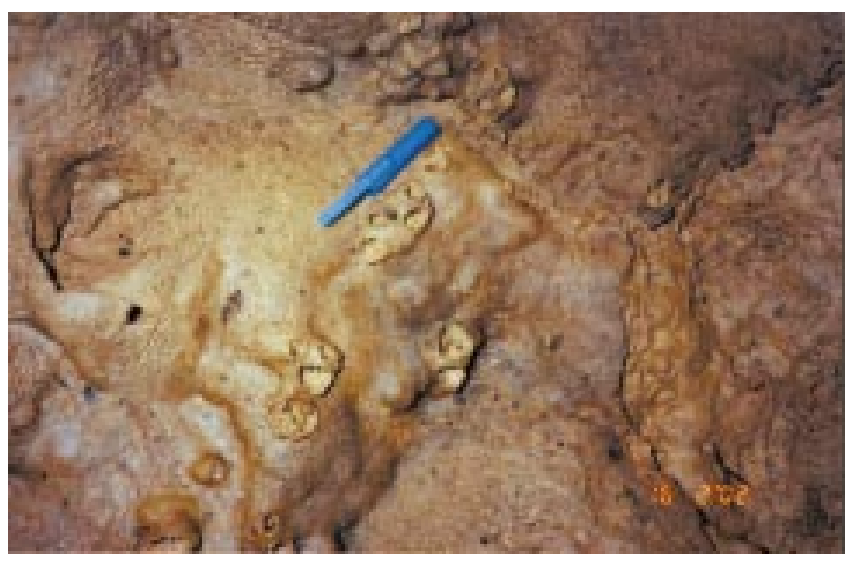

Foto 5 - Esferas de calcita (blisters), centimétricas, parcialmente fragmentadas, no final do conduto do rastejamento.

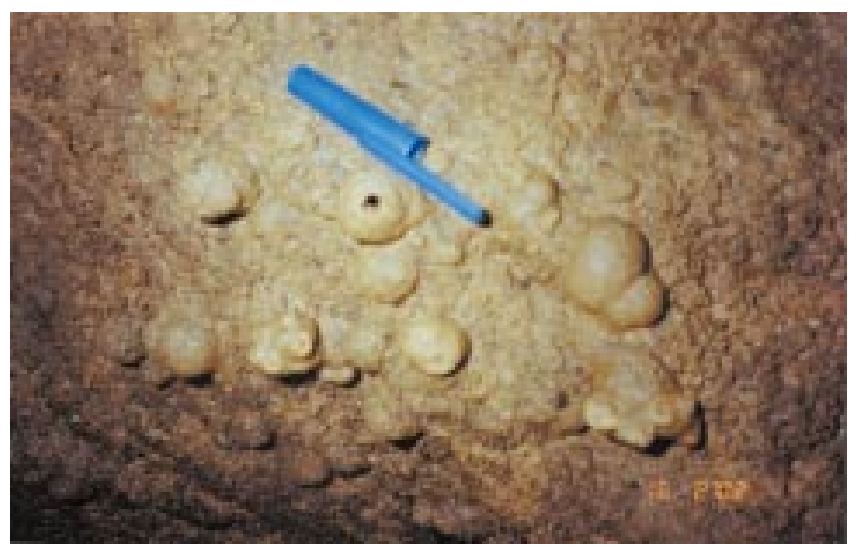

Foto 6 - Esferas de calcita, centimétricas, fechadas e com orifício central, fim do conduto do rastejamento.

de diâmetro. Algumas encontram-se em estágios embrionários de formação, outras encontram-se erodidas, fragmentadas. Algumas não têm o orifício central (as embrionárias) e são menores, com diâmetros de até um centímetro. Aquelas que estão fragmentadas apresentam só a "casca" quebrada. Essa casca é lisa, quase polida, por dentro e rugosa por fora.

É provável que a origem desses espeleotemas está ligada aos processos descritos anteriormente, isto é, eles podem ter sido gerados por ação de precipitação por exsudação e simul- 
taneamente com influência de expansão de gases aprisionados no interior das "pústulas", uma vez que a cobertura das mesmas apresenta-se "vedada" pela deposição de argila (lama). Com o crescimento da esfera, a força (pressão) do gás aprisionado rompe a "casca fina" da esfera originando os pequenos orifícios centrais.

Os helictites observados são de dimensões centimétricas a decimétricas (até $30 \mathrm{~cm}$ ) e de diversas formas. O maior observado, próximo do salão da calcita "dente-de-cão", tem a forma escalonada e mede $30 \mathrm{~cm}$ de comprimento.

Os helictites são originados por águas de exsudação, que, por capilaridade, circulam, lenta e descontinuamente pelos poros (Lino, 1989) da rocha ou pelos vazios intercristalinos de outros espeleotemas. A diferença de pressão existente entre os poros da rocha e o espeleotema e o vazio da cavidade faz com que essas soluções, ao emergirem da parede, depositem a calcita ou outro mineral dissolvido.

As calcitas "dentes-de-cão" ocorrem no teto do salão de mesmo nome, tendo dimensões milimétricas a até um centímetro de comprimento. As calcitas "dentes-de-cão" são depósitos de águas estagnadas. São espeleotemas originados a partir da deposição de minerais nas partes submersas dos represamentos de água que existem nas cavidades (Lino, 1989). Esses depósitos estão com soluções saturadas de carbonato de cálcio, que lentamente liberam o $\mathrm{CO}_{2}$ no ambiente da caverna. São depósitos erráticos, sem orientação preferencial e irregulares, com elementos cristalinos de muitas faces em projeções para o interi- or da cavidade. As calcitas "dentes-decão" são cristais de hábito romboédrico ou escalenoédrico, que podem revestir todas as paredes das cavidades preenchidas por soluções saturadas.

\section{Conclusões}

A gruta desenvolveu-se em rochas carbonáticas, estratificadas, dobradas e fraturadas da Formação Lagoa do Jacaré.

A cavidade tem a forma, em planta, linear meandrante, com perfil predominantemente horizontal e secundariamente inclinado.

O desenvolvimento da caverna envolve, pelo menos, quatro fases de evolução, desde o processo freático ao vadoso, com desenvolvimento dos salões por incasão.

Os salões finais da caverna são os mais ornamentados (fase vadosa) com ocorrências de vários espeleotemas, entre os quais se destacam, por sua beleza, os excêntricos (helictites), por sua raridade, os "blisters" ou esferas de calcita e, por sua gênese, os cristais de calcita "dente-de-cão".

\section{Agradecimentos}

Agradecemos ao Ibama/MG, nas pessoas da Sra. Ubaldina e do Sr. Jáder Pinto, pela pronta boa vontade no atendimento e liberação da licença para o acesso à caverna, à Prefeitura Municipal de Cordisburgo e à Fundação Maquinetur pelo acesso à Gruta do Maquiné. Agradecemos, ainda, à SEE (Sociedade Excursionista Espeleológica) pela cessão do mapa parcial da Gruta do Salitre e pelo uso de suas dependências físicas e equipamentos espeleológicos.

\section{Referências Bibliográficas}

ALKMIM, F.F., CHEMALE JR., F., BACELLAR, L.A.P., MAGALHÃES, P.M. Arcabouço estrutural da porção sul da bacia do São Francisco. In: SIMP. GEOL. DE MINAS GERAIS, 5, 1989. Belo Horizonte, Anais... Belo Horizonte: SBG, 1989.

BOAVENTURA, R.S., MOREIRA, C.V.R., BOAVENTURA, F.M.C. Mapa geomorfológico. Folha Belo Horizonte. Projeto Radar Minas Gerais, 1:500.000, Secretaria de Estado de Ciência e Tecnologia. Instituto de Geociências Aplicadas (IGA), 1977.

CAVALCANTI, J.A.D. Mapeamento espeleológico. Ouro Preto: SEE, 1996. 28p.

HILL C.A., FORTI P. Cave minerals of the World. 2. ed. Nat. Speleol. Soc., Inc., 1997. $463 \mathrm{p}$.

LINO, C.F. Cavernas, o fascinante Brasil subterrâneo. São Paulo: Editora Rios, 1989. $279 \mathrm{p}$

MAGALHÃES, L. Análise estrutural qualitativa dos sedimentos do Grupo Bambuí, região sudeste da Bacia São Francisco (Faixa Sete Lagoas - Serra do Cipó). Universidade Federal de Ouro Preto - Escola de Minas Departamento de Geologia, 1988. 85p. (Dissertação de Mestrado).

POBÉGUIN, T. Reproduction expérimentale de concrétions de carbonate de calcium. Ann. Spéléol., v. 12, n. 1-4, p. 5-12, 1957.

SBE (Sociedade Brasileira de Espeleologia). Cadastro nacional de cavidades naturais - índice de dados sobre as cavernas do Brasil. 1991.

TEIXEIRA DA SILVA, C.M. Espeleotemas: crescimentos fractais. Rev. Espeleologia, n. 9, p. 22-28, 1997.

VALLE, C.M.C. A Gruta ou Lapa Nova do Maquiné. Belo Horizonte: Líttera Maciel, 1991. $72 \mathrm{p}$.

\section{www.rem.com.br}

\section{remjorio@ouropreto.com.br}

